\title{
LAS BASES CONSTITUCIONALES DE LA POTESTAD SANCIONADORA DE LA ADMINISTRACIÓN*
}

\author{
["The Constitutional Foundations of the State Administration's Sanctioning
} Power"]

\author{
Eduardo Cordero Quinzacara** \\ Pontificia Universidad Católica de Valparaíso, Chile \\ Eduardo Aldunate Lizana ${ }^{* * *}$ \\ Pontificia Universidad Católica de Valparaíso, Chile
}

\begin{abstract}
RESUMEN
En este trabajo los autores analizan el problema de las bases constitucionales de la potestad sancionadora de la Administración, a partir de los criterios establecidos en la jurisprudencia del Tribunal Constitucional y las críticas que se han formulado por parte de la doctrina. Se parte por la determinación del concepto de autotutela administrativa, estable-
\end{abstract}

\begin{abstract}
In this work the authors analyze the problem of the constitutional foundations of the State Administration's sanctioning power, based on criteria established by the Constitutional Court and the criticism raised by the doctrine. On the first hand, the actual reach of the concept of administrative self-guardianship is determined and, on the other hand, it is asserted
\end{abstract}

ReCibido el 30 de octubre y ACEPTADo el 10 de noviembre de 2012.

* Este trabajo es parte de la investigación financiada por FONDECYT, bajo el № 1110791 y con el título: "Fundamentos y principios de la potestad sancionadora de la Administración del Estado en el Derecho chileno".

** Profesor de Derecho administrativo en la Facultad de Derecho de la Pontificia Universidad Católica de Valparaíso. Dirección postal: Pontificia Universidad Católica de Valparaíso, Facultad de Derecho, Avenida Brasil 2950, Valparaíso, Chile. Correo electrónico: eduardo.cordero@ucv.cl

*** Profesor de Derecho constitucional en la Facultad de Derecho de la Pontificia Universidad Católica de Valparaíso. Dirección postal: Pontificia Universidad Católica de Valparaíso, Facultad de Derecho, Avenida Brasil 2950, Valparaíso, Chile. Correo electrónico: ealdunat@ucv.cl 
ciendo su real alcance, para luego afirmar que los principios de eficacia y eficiencia constituyen el fundamento que permite al legislador residenciar la sanción de estos ilícitos en el marco de la Administración del Estado, dentro de una política represiva que se construye sobre el principio de un Derecho penal subsidiario y de una actuación estatal oportuna.

Palabras Clave

Sanciones administrativas - Constitución - Administración del Estado. that the effectiveness and efficiency principles are the grounds that allow the legislator to place the sanction of these illegal acts within the framework of the State Administration, within a repressive policy that is built on the principle of a subsidiary criminal law and on a timely public action.

KEYWORDS

Administrative sanctions - Constitution - State Administration

\section{CONSIDERACIONES PREVIAS}

Puede resultar fastidioso volver sobre la discusión respecto de la constitucionalidad de las sanciones administrativas en nuestro Derecho, pues de seguro quien lea el título de este trabajo se preguntará qué sentido tiene insistir en un tema sobre el cual las posiciones que existen están claramente expuestas y, sobre todo, que la realidad nos demuestra que se trata de una cuestión que no plantea mayor debate ni discusión en la jurisprudencia. Incluso, en el evento que se llegará al plantear la cuestión, es muy probable que los argumentos afloren fácilmente, pues es muy difícil ocultar una realidad tan desbordante como es la existencia de potestades punitivas en manos de la Administración, de la cual se demanda cada vez más su intervención, frente a posiciones que se pueden estimar jurídicamente plausibles, pero claramente irreales e impracticables.

Sin embargo, en el análisis del fundamento constitucional de la potestad sancionadora, es posible constatar la tendencia registrada en la literatura y jurisprudencia de los últimos años, al considerar como necesaria la existencia de fundamentos constitucionales de cualquier institución jurídica. Ello parece ser un efecto secundario de lo que se ha venido en llamar "la constitucionalización del Derecho". En efecto, si se afirma que todo el orden subconstitucional se encuentra "irradiado" por las disposiciones constitucionales, la conclusión a la que se puede arribar fácilmente es que para cada ámbito del ordenamiento jurídico bajo la constitución, se encuentra la respectiva cobertura constitucional. Ahora bien, esta posición sólo puede ser sostenida desde una deficiente concepción de la constitución y sus funciones, aunque deba anotarse que dicha deficiente concepción hoy es la predominante en doctrina y jurisprudencia. 
En efecto, si la constitución tiene como función principal el institucionalizar el proceso político, su regulación ha de ser, por necesidad, fragmentaria. De este modo, no se supone que cada institución del ordenamiento jurídico deba tener un sustento o fundamento constitucional sino que solamente aquellas instituciones que, en el proceso político, han sido objeto de pacificación a través del texto constitucional. De este modo, si bien en Chile, por ejemplo, resulta claro que la regulación constitucional de la propiedad da cuenta de un proceso particularmente intenso desde la década de 1950 hasta el golpe militar del año 1973, y la consecuente reacción (aseguradora) en lo que toca al derecho de propiedad, el análisis de la potestad punitiva del Estado, en particular de la sanción administrativa, debe responder a la exigencia de encontrarse incluida en las cuestiones políticamente relevantes, cosa que ha venido sucediendo el último tiempo, aunque no con la intensidad que permita justificar esta discusión a nivel de la Carta fundamental.

No obstante lo anterior, pensamos que puede ser necesario abordar la cuestión, especialmente cuando nos encontramos con que la discusión que se produce a dicho nivel ha llevado a pronunciamientos que resultan abiertamente contradictorios, frente a fenómenos jurídicos que en su estructura básica son similares, cuando no idénticos. Y es que la misión de la dogmática jurídica es tratar de desentrañar el sentido objetivo de las normas que integran el ordenamiento jurídico ${ }^{1}$, con la finalidad de garantizar la certeza y seguridad, valores que permiten crear un estado de paz social y de justicia. El Derecho no puede ser la ciencia de lo discutible, menos aún cuando lo que está en juego es la constante tensión entre interés público y bien común y derechos de las personas.

Por lo demás, el tema de las sanciones administrativas no es sino un trasunto de la posición que tiene la Administración frente al ordenamiento jurídico, especialmente en su deber de servicialidad y de promoción del bien común. El ordenamiento jurídico le atribuye poderes exorbitantes a los órganos administrativos en razón de la función que debe cumplir, lo cual le permite alterar la situación jurídica de terceros aún en contra de su voluntad y, más aún, ejecutar directamente sus propias decisiones. Sin embargo, aun cuando se reconozca el sentido y fundamento de este "privilegio" a favor de los órganos que integran la Administración pública, surgen voces que la cuestionan y plantean una visión distinta para comprender e interpretar las normas jurídico-públicas. Tal como lo expresa Alejandro Nieto, los infractores poderoso no sólo tienen abogados que los defiendan, sino también

\footnotetext{
${ }^{1}$ Radbruch, Gustav, Introducción a la Filosofía del Derecho (México, Fondo de Cultura Económica, 2005), p. 9.
} 
autores que magnifican su posición de víctimas; mientras que la colectividad anónima e indigente apenas encuentra quien la defienda o escriba en atención a intereses generales que les afectan ${ }^{2}$. De aquello podemos encontrar muchos ejemplos.

En el caso que nos convoca, la discusión no se ha planteado en los términos de fijar límites a la potestad sancionadora de la Administración, tradicionalmente considerada como un ámbito en donde los derechos y garantías de los particulares se atenúan de forma considerable, por no decir que prácticamente desaparecen. En efecto, los intentos por reconducir su régimen jurídico sobre los principios básicos del poder punitivo penal o de establecer las garantías de racionalidad y justicia que demandan un procedimiento de esta naturaleza, no ha sido suficiente. El problema no es la racionalización en el ejercicio de esta potestad punitiva, sino derechamente cuestionar su constitucionalidad y, por tanto, su existencia dentro de nuestro ordenamiento jurídico ${ }^{3}$. No se trata de un problema nuevo, pues desde antiguo han existido algunas discusiones sobre el régimen al cual se deben someter las infracciones administrativas. Así, una posibilidad sería la de judicializarlas, como ocurrió en Francia y Alemania, mientras que otras es mantenerlas en manos de la Administración, ya sea porque se considera que en este ámbito se da una respuesta más cabal y oportuna a este tipo de materias o porque son cuestiones que normalmente están bajo su competencia, como ha sucedido en España e Iberoamérica en general ${ }^{4}$. Sin embargo, el problema ha sido el de trasladar un tema de discusión política al plano jurídico, utilizando como punto de conexión a la constitución. Desde tan magna y alta perspectiva, no sólo resulta fácil imponerse sobre la doctrina, sino también cuestionar

${ }^{2}$ Nieto, Alejandro, Derecho administrativo sancionador ( $4^{a}$ edición, Madrid, Tecnos, 2011), p. 41.

${ }^{3}$ En este sentido, se puede consultar Soto Kloss, Eduardo, El Derecho administrativo penal (Notas para el estudio de la potestad sancionadora de la Administración), en Boletín de Investigaciones, 44-45 (Facultad de Derecho, Universidad Católica de Chile, 1979-1980), pp. 95-103; y La potestad sancionadora de la Administración, ¿Se adecua a la Constitución? (Conferencias Santo Tomás, Sanciones Administrativas y Derechos fundamentales: regulación y nuevo intervencionismo, Santiago, Academia de Derecho, Santiago Universidad Santo Tomás, 2005), pp. 29-49. A su vez, hay autores que adhieren en principio a esta tesis, pero aceptan la posibilidad de proyectar los principios penales al ámbito administrativo. Véase Aróstica Maldonado, Iván, Problemas del Derecho administrativo penal, en Revista de Derecho, 182 (Universidad de Concepción, 1987), p. 71; y El MISMO, Un lustro de sanciones administrativas (1988-1992), en Revista de Derecho Público, 50 (1991), p. 173 ss.

${ }^{4}$ Sobre la materia, se puede consultar el interesante trabajo de HuErgo Lora, Alejandro, Las sanciones administrativas (Madrid, Iustel, 2007), pp. 53-133, donde se hace un análisis del sistema alemán, francés e italiano de sanciones administrativas, además de una síntesis de la situación en el Derecho comunitario europeo. 
al legislador positivo, que se transforma en una suerte de pecador jurídico contumaz, al infringir de forma reiterada no lo que dice la constitución, sino lo que el autor sostiene que dice la constitución.

Por tales razones, hemos vuelto sobre el tema, especialmente porque las soluciones y respuestas que se han dado sobre esta materia no resultan -a nuestro parecer- del todo satisfactorias. Así, muchas de ellas justifican el poder sancionador de la Administración en el plano de la necesidad y conveniencia, sin que apenas se entreguen argumentos jurídicos positivos que permitan enfrentar unos cuestionamientos que aparecen expuestos de forma simple, pero que encierran más de una dificultad al momento de argumentar en contrario 5 . También debemos reconocer que no es cómodo construir un análisis como reacción a un cuestionamiento en contrario, ya que todo esto puede generar una discusión en donde sólo queda alinearse con una de las posiciones o tomar palco. Pero siempre es bueno hacer el esfuerzo, plantear nuestra posición y someterse al escrutinio, análisis y crítica de nuestros colegas. Es mejor que sea así, antes de soslayar una discusión del todo necesaria.

\section{EL PROBLEMA DE LAS SANCIONES ADMINISTRATIVAS: REALIDAD HISTÓRICA Y CONSTITUCIÓN}

Uno de los problemas con los que habitualmente se enfrenta la norma constitucional es respeto de aquella realidad asentada en la tradición y la costumbre inveterada. En más de una ocasión nos hemos encontrado que la justificación de una institución se basa precisamente en aquello: la idiosincrasia, su reconocimiento multisecular o el uso inmemorial. Sin embargo, no es posible admitir que, por muy antigua o tradicional que fuese una institución, ésta se mantenga vigente aún en contra lo prescrito por la constitución. Con aquello no sólo se refuerza el carácter normativo de la carta fundamental, sino que obligaba al operador jurídico a argumentar sobre la base de textos normativos, en lugar de buscar en los hechos elementos que sólo debiese estar en el Derecho.

Este es el problema que se plantea con las sanciones administrativas. Como lo ha demostrado la doctrina, la existencia de poderes punitivos en manos de la Administración responde a una suerte de persistencia histórica ${ }^{6}$. Una vez que se asientan los principios revolucionarios liberales (separación

\footnotetext{
${ }^{5}$ Véase, en este sentido, Román Cordero, Cristian, Derecho administrativo sancionador: ¿Ser o no ser? He aqui el dilema, en Pantoja, Rolando (coordinador), Derecho administrativo. 120 años de cátedra (Santiago, Editorial Jurídica de Chile), pp. 107-141.

${ }^{6}$ Véase Mattes, Hans, Problemas de Derecho penal administrativo, en Revista de
} 
de poderes, reconocimiento de derechos inherentes a las personas, soberanía popular, supremacía constitucional, etc.) y se expande el modelo en los diversos Estados occidentales, se mantienen en manos de la Administración poderes sancionadores heredados del antiguo régimen. Varias son las razones de este lastre histórico: se trataría de ilícitos de menor importancia; su conocimiento por parte de los tribunales puede significar una cantidad de trabajo y esfuerzo que puede superar sus fuerzas y la buena marcha de administración de justicia; o son asuntos más cercanos a la Administración en razón del interés y materia que comprenden. Todos estos argumentos tratan de dar una explicación a una realidad que es evidente: la imposibilidad de aplicar en su integridad el principio de separación de los poderes y la garantía de un Derecho penal judicializado. Esto transformaría a las sanciones administrativas en una realidad tolerada constitucionalmente: existen porque han existido siempre; porque es una institución asentada en el tiempo; porque son ilícitos menores que no exigen de todo el sistema de garantías del Derecho penal, en definitiva, ningún fundamento positivo.

El tema se hace más espinudo cuando se incrementa la intervención del Estado en la sociedad, frente a una demanda creciente por solucionar diversos problemas del orden social: salubridad pública, urbanismo, tránsito público, etc. En estos casos, la potestad sancionadora de la Administración aparece como una herramienta de enorme eficacia para responder a estas demandas sociales. El desarrollo y la nueva dinámica de las estructuras sociales no encuentra satisfacción sólo en la garantía de legalidad, que es el bien que puede proveer el aparato judicial. Menos aún, si está sometida a toda las formas y a la ritualidad de los procesos judiciales. En este caso, al interior el aparato público la Administración aparece como el complejo orgánico que puede garantizar un cierto orden, responder a estas demandas sociales y dar protección de bienes jurídicos supra-individuales, ejerciendo entre otras herramientas, un poder punitivo directo. En este escenario, la sanción administrativa no sólo es una herencia histórica, sino que se trata de una herramienta que debe ser reforzada y estimulada como uno de los principales mecanismos de acción del aparato público. Por tanto, los juristas no pueden evadir el problema dogmático y deben dar una respuesta a nueva realidad jurídica en expansión.

Derecho Privado (Madrid, 1979). También se puede consultar Nieto, cit. (n. 2), pp. 53 ss. 


\section{UNA SOLUCIÓN JURISPRUDENCIAL: EL “IUS PUNIENDI" ÚNICO DEL ESTADO}

La realidad nos demuestra que el problema central de las sanciones administrativa no ha estado en su fundamento constitucional, sino en los mecanismos que puede establecer el ordenamiento jurídico para racionalizar su ejercicio conforme a los principios básicos que rigen en el orden punitivo penal. Bien señalaba un autor que las sanciones administrativas evocan muchas veces a un Derecho penal prebeccariano, carente de las garantías mínimas propias de un Derecho punitivo liberal 7 . Es el espacio de las normas administrativa y no de ley; las conductas que se sancionan se describen de forma ambigua e imprecisas, bastando en la mayoría de las ocasiones la simple infracción de reglamento como tipo sancionador; no hay espacio a la culpabilidad, ya que se entiende que la responsabilidad sería objetiva; el derecho a la defensa y a un justo y racional procedimiento queda entregado a la voluntad de la Administración; el control judicial se ve condicionado (solve et repete) cuando no derechamente restringido.

Esta es la constatación que tanto la doctrina nacional ${ }^{8}$ como extranjera $^{9}$ ha realizado. Por su parte, este el camino que también ha seguido nuestro Tribunal Constitucional, el cual no se ha planteado cuestión alguna sobre la constitucionalidad de las sanciones administrativa, ya que su legitimidad en este plano la da por supuesta, preocupándose del tema de los principios y normas constitucionales a las cuales se encuentran sujetas.

Una segunda cuestión que requiere de precisión, desde la perspectiva constitucional, es el asentado uso -que se se mantiene, en todo caso, a lo largo de este artículo a fin de no dificultar la comprensión de un lector- de la idea de un ius puniendi del Estado, como una facultad identificable y que podría incluir algunas categorías tales como la posibilidad de aplicar sanciones penales y administrativas. No existe nada nocivo en el uso de la expresión, de no ser porque conlleva la idea de una potestad específica, diferenciada de otras y sin la cual el Estado no podría aplicar sancionesde cualquier tipo. En nuestra opinión este enfoque puede inducir a error. La denominada facultad sancionadora del Estado, el ius puniendi en cualquiera de sus manifestaciones, no es una cosa distinta a la facultad general sobre la que descansa el ejercicio del poder público: adoptar medidas que, desde el punto de vista de los individuos pueden ser apreciadas como afectación de sus derechos, en general; más precisamente, de sus derechos fundamentales, ya sea bajo la

${ }^{7}$ GARCÍA de ENTERría, Eduardo, El problema jurídico de las sanciones administrativas, en Revista de Derecho Administrativo, 10 (1976), pp. 399-430.

${ }^{8}$ Soto Kloss, E., cit. (n. 3); y Aróstica, I., cit. (n. 3).

${ }^{9}$ Entre los más destacados, véase García de Enterría, E., cit. (n. 7). 
forma de afectaciones regulatorias, ya bajo la más concreta manifestación de intervenciones.

\section{LA JURISPRUDENCIA CONSTITUCIONAL}

Nuestra jurisprudencia constitucional se ha hecho cargo del problema con mayor intensidad en época reciente, a partir de 2006, con una aislada pero relevante sentencia de 1996 . Es posible sintetizar la doctrina contenida en sus pronunciamientos en base a los siguientes puntos:

1. No se cuestiona la constitucionalidad de las sanciones administrativas, pero tampoco se fundamenta su legitimidad.

En primer lugar, el Tribunal Constitucional no plantea reparo ni cuestionamiento alguno respecto de la constitucionalidad de las sanciones administrativas. Todo lo contrario, considera legítimo que el legislador le confiera estos poderes a los órganos de la Administración, aunque siempre sujeto a la revisión judicial ulterior. Al efecto, ha señalado: “[... si bien puede resultar licito que los órganos fiscalizadores puedan, previo al proceso judicial y en el ámbito administrativo, determinar la existencia de una infracción y la cuantia de una multa, la sanción no puede estimarse como cierta e irrevocable para el ordenamiento jurídico sino una vez que no haya sido reclamada $o$ que, habiéndolo sido, tal reclamo haya sido resuelto en sede jurisdiccional e independiente. Asi lo consagra nuestro sistema al permitir que se recurra de las respectivas decisiones administrativas ante los tribunales, cuestión que no sólo está consagrada a nivel legal, sino que también, con mayor jerarquia, en la propia Constitución Politica (articulo 38, inciso segundo)". (considerando $6^{\circ}$ de la sentencia rol No 792, de 3 de enero de 2008). Sin embargo, el Tribunal Constitucional omite cualquier pronunciamiento respecto de los fundamentos constitucionales de la potestad sancionadora de la Administración.

2. La potestad punitiva de la Administración es de naturaleza administrativa y no penal.

Por su parte, también el Tribunal Constitucional ha señalado que el ejercicio de potestades punitivas por parte de los órganos de la Administración del Estado es de naturaleza administrativa y no penal. Así, en materia tributaria ha dicho que: " [...] en la especie, sin embargo, no existe ejercicio de facultades propiamente jurisdiccionales, que resuelvan conflictos entre partes, sino que se trata de potestades administrativas sancionadoras [...] como lo ha señalado la doctrina, "un elemento básico de la sanción administrativa es el carácter administrativo del procedimiento que ha de observarse. El procedimiento aparece gobernado y dirigido, principalmente, por órganos y funcionarios 
integrantes de la Administración" (Ramiro Mendoza, Acerca del principio general de la intransmisibilidad de las multas, Conferencias Santo Tomás, 2005, p. 137)" (considerandos $13^{\circ}$ y 14 de la sentencia rol No 766-2007, de 26 de junio de 2008. Lo mismo en las sentencias rol o 725 , de la misma fecha; rol No 1.223, de 30 de diciembre de 2008; rol No 1.245, 1.203, 1.221, $1.229,1.183,1.184$ y 1.205 , todas de 8 de enero de 2009 ; rol No 1.233 , de 13 de enero de 2009).

3. Existe una identidad ontológica entrepenasy sanciones administrativas, como expresión del "ius puniendi" único del Estado.

Siguiendo la tendencia comparada - particularmente española ${ }^{10}$ - el Tribunal Constitucional afirma que la potestad punitiva penal y administrativa son manifestaciones del poder único que tiene el Estado para sancionar determinadas conductas, existiendo, por tanto, una identidad ontológica entre una y otra. Leemos, así, en una senteciua: "Que, losprincipios inspiradores del orden penal contemplados en la Constitución Política de la República han de aplicarse, por regla general, al Derecho administrativo sancionador, puesto que ambos son manifestaciones del ius puniendi propio del Estado" (considerando $9^{\circ}$ de la sentencia rol No 244, de 26 de agosto de 1996). Y en otra: "Aún cuando las sanciones administrativas y las penas difieren en algunos aspectos, ambaspertenecen a una misma actividad sancionadora del Estado - el llamado iuspuniendi-y están, con matices, sujetas al estatuto constitucional establecido

${ }^{10}$ Esta regla básica tiene su origen en la jurisprudencia del Tribunal Constitucional español (sentencias de 30 de enero y 8 de junio, de 1981), la que a su vez fue tomada de la jurisprudencia preconstitucional del Tribunal Supremo español. La sentencia del Tribunal Supremo, de 31 de octubre de 1972, señalaba a este respecto que "el supuesto de hecho de que se trata [...] pertenece al capitulo especial del Derecho Administrativo, esto es, al Derecho administrativo sancionador, llamado también por muchos Derecho penal administrativo, no sin falta de fundamento, puesto que, a lo largo de la historia, se presenta todo un trasiego de infracciones del Derecho penal común, al Derecho que acabamos de llamar penal administrativo, o viceversa [...] lo que revela la necesidad imperiosa de que existan unos principios generales, y un cuerpo de doctrina que cubran uno u otro campo, por darse en los dos unas mismas exigencias, como son el principio de legalidad [...] ya que, si por un lado, el derecho sancionador representa la protección más enérgica de los bienes necesitados de una protección especial, por otro, este mismo rigor demanda, en contrapartida, las máximas garantías para el encausado, entre ellas, además de las antes apuntadas, la que puede considerarse como idea básica de todo el derecho punitivo y sancionador: la que fundamenta el principio «in dubio pro reo". Esta teoría de la identidad ontológica entre infracción administrativa y delito es sostenida actualmente en España por la mayoría de la doctrina y la totalidad de la jurisprudencia, aun cuando ha sido duramente criticada en el último tiempo, especialmente a partir de los trabajos del profesor Alejandro Nieto, cit. (n. 2), y que ha sido de obligada referencia en las obras y comentarios posteriores. 
en el numeral $3^{\circ}$ del artículo 19" (considerando $5^{\circ}$ de la sentencia rol $\mathrm{N}^{\circ} 480$, de 27 de julio de 2006. Lo mismo en Considerando $8^{\circ}$ de la sentencia rol $N^{\circ}$ 479, de 8 de agosto de 2006).

El principal objeto de esta posición es establecer el régimen jurídico aplicable a las sanciones administrativas, como consecuencia de la ausencia de una regulación general de las mismas y de los problemas que esto puede plantear. De esta forma, el Tribunal Constitucional nos señala que los principios que orientan e inspiran el orden penal han de aplicarse al Derecho administrativo sancionador. Sin embargo, esta aplicación no es mecánica ni directa, pues exige de parte del operador jurídico hacer algunos matices, los cuales no se indican ni tampoco se entregan las pautas sobre las cuales se debe realizar dicha labor.

En el ordenamiento comparado, especialmente en el español, la relación entre el Derecho penal y el Derecho administrativo sancionador se resolvió en una primera etapa sobre la base de la supletoriedad y el llenado de lagunas. Bien dirá Nieto que la presencia del Derecho penal cumple una función de garantía y freno impuesto por el Derecho a la libre y tendencialmente autoritaria intervención de la Administración ${ }^{11}$. El paso siguiente fue la aplicación directa de los principios del Derecho penal, sin que sea necesaria la existencia de lagunas o vacios. Sin embargo, es en este punto donde se impone a los operadores jurídicos (Administración y Juez) una labor de modulación de estos principios, de manera que se adapten a la naturaleza propia de las sanciones administrativas. En buenas cuentas, se trata de una remisión sin contenido, quedando entregado al criterio de la autoridad el establecimiento de estas reglas y matices. En este caso, el problema será determinar "que" principios serán aplicados y "hasta que punto" o intensidad van a serlo ${ }^{12}$.

\section{En virtud de lo anterior, tanto las penas como las sanciones administra-} tivas están sujetas a un estatuto constitucional común.

La tesis de la identidad ontológica entre penas y sanciones administrativas permite al Tribunal Constitucional sujetar a ambas a un mismo estatuto constitucional. Esto era, por lo demás, una interpretación que ya había sido sostenida por la doctrina nacional ${ }^{13}$. Así se reconocen un conjunto de garan-

${ }^{11}$ Nieto, cit. (n. 2), p. 165.

${ }^{12}$ Ibíd.

${ }^{13}$ Véase Rodriguez Collado, Luis, Bases para distinguir entre infracciones criminales y administrativas, en Revista de Derecho de la Pontificia Universidad Católica de Valparaiso, 11 (1987), p. 117; Aróstica Maldonado, I., Un lustro, cit. (n. 3); Aguerrea Mella, Pedro, El estatuto constitucional de la penas. Su aplicación a las sanciones administrativas conforme a los antecedentes de la Comisión de Estudio de la Nueva Constitución, en AA.VV., Sanciones administrativas y derechos fundamentales: 
tías mínimas tanto sustantivas como procedimentales: legalidad, tipicidad, culpabilidad, irretroactividad, justo y racional procedimiento previo. ${ }^{14}$

Además, la sanción administrativa siempre es revisable por la vía judicial, como consecuencia del derecho de acceso a la justicia ${ }^{15}$.

\section{La atribución depotestades sancionadoras a la Administración constituye} una cuestión de mérito que debe resolver el legislador, aunque sujeta a ciertos limites.

El Tribunal Constitucional también ha sostenido que la posibilidad de que una determinada conducta sea sancionada por la vía administrativa o judicial, es una cuestión de política legislativa, cuya determinación queda entregada, en principio, al juicio de mérito que al respecto realice el Legislador ${ }^{16}$. Sin embargo, se trata de una facultad que está sujeta a algunos límites, como los siguientes:

a)El Legislador al momento de determinar la sanción debe aplicar el

regulación y nuevo intervencionismo (Santiago, Universidad Santo Tomás, 2005), pp. 51-62.

${ }^{14}$ Cfr. sentencias rol Nos 244 , de 1996; 479 y 480, de 2006; 725 y 766 , de 2008; $1.183,1.184,1.203,1.205,1.221$ y 1.229, de 2009; y 1.518, de 2010. Más aún, expresamente el Tribunal Constitucional ha señalado que las sanciones administrativas participan de los elementos esenciales de las sanciones penales (considerando $6^{\circ}$ de la sentencia rol No 1.518 , de 2010).

${ }^{15}$ Entre otras, la sentencia rol No 792 , de 3 de enero de 2008.

${ }^{16}$ En este sentido, el Tribunal Constitucional ha señalado que "[...] no debe desconocerse la circunstancia de que, aunque se trata de una cuestión de mérito que debe resolver el legislador, se ha cuestionado la circunstancia que sea la propia administración la que conozca de materias sancionatorias". Cfr. el considerando $28^{\circ}$, de la sentencia rol $\mathrm{N}^{\circ} 725$, de 2008. En el mismo sentido véanse las sentencias rol № 766, de 26 de junio de 2008, y $\mathrm{N}^{\circ} 1.223$, de 30 de diciembre del mismo año. Al efecto el Tribunal Constitucional ha señalado que "reparos en tal sentido puede apreciarse incluso en la doctrina de ius publicistas de fines del siglo XIX (Jorge Huneeus, La Constitución ante el Congreso, 1891). Ello se reitera en las postrimerías del siglo XX (Eduardo Soto Kloss e Iván Aróstica Maldonado, por mencionar algunos). En tal sentido un autor ha señalado que 'una somera revisión de la legislación vigente en esta materia, en un diagnóstico preliminar, nos lleva a plantear un serio cuestionamiento acerca del contenido y alcances de las sanciones administrativas, de la forma como el legislador ha venido configurando la potestad sancionadora, del modo como dicha atribución está siendo ejercida por parte de la administración y del control de su ejercicio por parte de los tribunales' (Pedro Aguerrea, Acerca de los límites de la potestad sancionadora de la administración, 2005) [...] por lo demás, ya en las X Jornadas del ILADT, celebradas en 1981, se propugnaba que 'todas las sanciones por infracciones tributarias sean aplicadas por órganos jurisdiccionales'. Del mismo modo, el jurista Niceto Alcalá Zamora y Castillo, en la I Jornada Latinoamericana de Derecho Procesal, instaba a que "el castigo de las infracciones administrativas debe sustraerse a la administración y traspasarse a genuinos tribunales mediante un procedimiento sumario". 
principio de proporcionalidad, considerando la intensidad de la limitación que se impone a un derecho fundamental y el objetivo constitucional válido que se busca perseguir: "una limitación a un derecho fundamental es justificable, cuando dicho mecanismo es el estrictamente necesario o conveniente para lograr un objetivo constitucionalmente válido, debiendo consecuentemente el legislador elegir aquellas limitaciones que impliquen gravar en menor forma los derechos fundamentales" 17 .

b) Las penas privativas de libertad sólo se pueden imponer previa intervención de la autoridad judicial (artículos $19 \mathrm{~N}^{\text {os }} 1$ y 7 C.Pol.). En este sentido, ha señalado que una disposición "infringe lo dispuesto en el artículo 19 , números $1^{\circ}$ y $7^{\circ}$, de la Constitución, desde que se trata de un verdadero apremio ilegitimo, al importar una pena privativa de libertad impuesta por la via administrativa y sin que previamente exista una instancia jurisdiccional que revise dich a actuación" 18 .

c) Por último, tampoco es posible que una sanción administrativa de multa pueda ser convertida por vía sustitutiva en una pena privativa de libertad, a diferencia de lo que ocurre con las sanciones penales. Nuevamente en este caso se coloca como elemento determinante la no intervención judicial en la medida que decreta la privación de libertad.

\section{Sanción administrativa, Administración y aUto-TUtela}

\section{Los privilegios y prerrogativas de la Administración.}

El tema de la constitucionalidad de las sanciones administrativas entronca con uno de los conceptos fundamentales del Derecho administrativo: el privilegio de la autotutela administrativa. Justamente éste ha sido uno de los puntos sobre los cuales se ha centrado la discusión y exige un análisis desde su base el problema.

En efecto, con el objeto de explicar los elementos esenciales que caracterizan a nuestro Derecho administrativo, se ha recurrido a la influencia francesa que caracteriza a esta disciplina sobre la base de los privilegios y prerrogativas que le atribuye el ordenamiento jurídico. Como bien lo señala Juan Carlos Ferrada, siguiendo a Laubadére, el Derecho administrativo francés estará asociado desde un principio a la existencia de prerrogativas o potestades públicas, las que precisamente le permiten ejercer su actividad por encima de los derechos e intereses privados, fundadas precisamente en

${ }^{17} \mathrm{La}$ aplicación del principio de proporcionalidad aparece aplicado en general en las sentencias rol $\mathrm{N}^{\mathrm{os}} 226$, considerando $47^{\circ} ; 280$, considerando $21^{\circ}$; y 519 , considerando $19^{\circ}$. En relación con las sanciones administrativas en particular, se puede ver la Sentencia rol No 1.518 , considerando $14^{\circ}$.

${ }^{18} \mathrm{Cfr}$. El considerando $22^{\circ}$ de la sentencia rol № 1.518 . 
los intereses públicos que tutela ${ }^{19}$. Esta influencia se habría manifestado en nuestra doctrina desde sus orígenes, como aparece en la obra de Santiago Prado $^{20}$ y seguida por autores tan influyentes como Guillermo Varas ${ }^{21}$, Patricio AylwinAzócar ${ }^{22}$ y Enrique Silva Cimma ${ }^{23}$, pero que ha tenido reputados detractores, desde Jorge Huneeau ${ }^{24} \mathrm{y}$, en época más reciente, Eduardo Soto $\mathrm{Kloss}^{25}$, con notable peso e influencia ${ }^{26}$.

Sin embargo, es imposible soslayar que el ordenamiento jurídico atribuye diversos poderes jurídicos a los órganos que integran la Administración del Estado y que lo colocan en una posición de superioridad frente a los particulares, en razón de los intereses públicos y generales que se deben satisfacer: la expropiación por causa de utilidad pública o interés nacional, la potestad invalidatoria y revocatoria de los actos administrativos, la ejecución de oficio de sus actos, etc. ¿Puede acaso cuestionarse desde una perspectiva constitucional dichas facultades o poderes?

Por su parte, ha sido la doctrina europea - particularmente italiana y española ${ }^{27}$ - la que ha comprendido este privilegio de la Administración

${ }^{19}$ Ferrada Bórquez, Juan Carlos, Los principios estructurales del Derecho administrativo chileno: un análisis comparativo, en Revista de Derecho, 221-222 (Universidad de Concepción, enero-diciembre de 2007), pp. 99-136.

${ }^{20}$ Prado, Santiago, Principios elementales de Derecho administrativo chileno (Santiago, Imprenta Nacional, 1859), p. 20.

${ }^{21}$ Varas, Guillermo, Derecho administrativo (Santiago, Editorial Nascimento, 1940)

${ }^{22}$ Aylwin, Patricio, Derecho administrativo (Santiago, Editorial Universitaria, 1959), dos volúmenes.

${ }^{23}$ Silva Cimma, Enrique, Derecho administrativo chileno y comparado. Introducción y fuentes ( $5^{a}$ edición, Santiago, Editorial Jurídica de Chile, 2009), p. 32 ss.

${ }^{24}$ Huneeus, Jorge, La Constitución ante el Congreso (Santiago, Imprenta de Los Tiempos, 1879), II, pp. 214 ss.

${ }^{25}$ Soto Kloss, Eduardo, Derecho administrativo (Santiago, Editorial Jurídica de Chile, 1992), I, p. 28; y II, pp. 17-19, y, del mismo autor, Derecho administrativo. Temas fundamentales (Santiago, LegalPublishing, 2009), pp. 389-398.

${ }^{26}$ Sobre la materia se puede consultar el interesante trabajo de FerRada BórQUEZ, Juan Carlos, Las potestades y privilegios de la Administración Pública en el régimen administrativo chileno, en Revista de Derecho de la Universidad Austral de Chile, 20 (diciembre de 2007) 2, pp. 69-94.

${ }^{27}$ Véase Benvenuti, Feliciano, voz "Autotutela (Diritto amministrativo)", en Enciclopedia del Diritto (Milano, Giuffré, 1959), IV, pp. 539-540. En el caso español destacan los trabajos de García DE ENTERRÍA, Eduardo, La formación histórica del principio de autotutela de la Administración, en Moneda y Crédito, 128 (1974), pp. 5987; y del mismo autor, Revolución francesa y Administración contemporánea (2a edición, Madrid, Taurus, 1981), recogida posteriormente en su Curso de Derecho administrativo, en conjunto con Tomás-Ramón Fernández. 
bajo la denominación de auto-tutela admininistrativa, lo cual exige analizar su naturaleza y alcance.

\section{Naturaleza y alcances de la auto-tutela administrativa.}

Se ha entendido por auto-tutela administrativa la posición que tiene la Administración frente al ordenamiento jurídico y a los Tribunales de Justicia, para crear, modificar o extinguir situaciones jurídicas de terceros, aun en contra de su voluntad y, en su caso, para ejecutar materialmente sus propias decisiones. Por tal razón se distingue entre auto-tutela declarativa y la auto-tutela ejecutiva. En expresión de Eduardo García de Enterría, el sometimiento general de los sujetos de Derecho al principio de "paz jurídica" implica la carga de postular la tutela judicial de los derechos, tanto en el aspectos declarativo de éstos como en el ejecutivo, o imposición de hecho frente a las resistencias privadas, siendo el fenómeno de auto-tutela algo excepcional en las relaciones privadas, además de ser facultativa y no obligatoria. En cambio, la auto-tutela de la Administración es, en primer término, general y luego define un ámbito necesario de actuación que el juez no puede interferir salvo en un momento muy concreto de su desarrollo ${ }^{28}$. El mismo autor ha destacado la forma como la autotutela se ha configurado históricamente producto de un largo proceso y que la hace identificable como un principio general del ordenamiento jurídico. Así, la Administración puede tutelar por sí misma sus propias situaciones jurídicas, incluso sus pretensiones innovativas del statu quo, eximiéndose de la necesidad, común a los demás sujetos, de recabar la tutela judicial. ${ }^{29}$

Esto permite comprender la forma de actuar que tienen los órganos de la Administración en su relación con los particulares, con el objeto de resguardar los intereses generales que le han sido asignados, lo cual no es óbice para que tales actuaciones sean objeto de revisión ulterior por al vía judicial.

Sin embargo, este principio tan asentado ha sido objeto de serios cuestionamientos en Chile, particularmente respecto del ejercicio de la potestad de invalidación de los actos administrativos y de la potestad sancionadora de la Administración, que es el tema central de este trabajo.

La crítica, desarrollada principalmente por Eduardo Soto Kloss, se ha centrado en cuestionar la auto-tutela en general y la potestad sancionadora en particular. En el primer caso, sostiene que la auto-tutela “[...] se encuentra proscrita por el ordenamiento, y considerada ilícita, tanto más que transformarse en 'comisión especial' ( 19 No 3 inciso $4^{\circ}$ Constitución) constituye un

\footnotetext{
${ }^{28}$ García de Enterría, Eduardo - Fernández, Tomás-Ramón, Curso de Derecho administrativo (10ª edición, Madrid, Civitas, 2001), I, pp. 505-508, pp. 505-508.

${ }^{29}$ Ibíd.
} 
"contemptus iudici", es decir un "menosprecio de la judicatura", que es la única autoridad pública estatal que de modo exclusivo y excluyente le ha sido dada por la Constitución (artículo $73 \mathrm{sic}$ ) la potestad jurisdiccional, es decir "hacer justicia", quienesquiera sean las partes contendientes[...] Y es que esa auto-tutela significa alterar-de propia mano- el statu quo existente en las situaciones jurídicas producidas precedentemente por la propia actividad de la Administración, a través de sus propios actos[...] Auto-tutela que implica, además, una vulneración muy clara y patente de una de las bases de todo sistema republicano democrático, cual es la igualdad ante el Derecho y en el el Derecho, proscribiendo "toda persona o grupo privilegiado" (artículo 19 № 2 Constitución) y ivaya qué privilegio mayúsculo; sería el hacer justicia por si mismo[...]"30.

Respecto de la potestad sancionadora, nos señala que sancionar es "castigar”, imponer una pena, una aflicción en el ser o en tener del infractor, lo cual requiere un juicio de reproche frente a una conducta, juicio que debe ser racional y exige escuchar al presunto infractor. Además, quien emite este juicio debe ser independiente e imparcial, carente de interés respecto de ellas; en otros términos, que reúnan las calidades, condiciones, requisitos o exigencias indispensables propias de un juez. Sancionar es propiamente resolver una contienda entre partes, función propia de un juez. Por lo tanto, las potestades sancionadoras en manos de la Administración serían un atentado al derecho al juez natural (artículo $19 \mathrm{~N}^{\circ} 3$ inciso $4^{\circ}$ ) y sólo puede ser de competencia de los tribunales determinados por la ley, ya que no corresponde ni al presidente de la República ni al Congreso Nacional ejercer funciones jurisdiccionales (artículo 76 C.Pol.). A su vez, las leyes que atribuyen dichas potestades serían inconstitucionales, por infringir las garantías y derechos fundamentales de la persona, a cuyo servicio. "[...] como órgano del Estado que son el legislador y los órganos de la Administración, ellos están por imperativo constitucional (artículo 1 inciso $4^{\circ}$ C.Pol.)" ${ }^{31}$

Esta posición tuvo una singular recepción por parte de la jurisprudencia de la Corte Suprema en relación a las facultades de fiscalización ejercidas por la Dirección del Trabajo, al sostener que la determinación de infracciones administrativas a la legislación laboral y la aplicación de sanciones por parte de este organismo era ilegal y arbitraria, al constituirse en una suerte de comisión especial (artículo $19 \mathrm{~N}^{\circ} 4$ inciso 4 C.Pol.) y arrogarse facultades jurisdiccionales propias de los tribunales de justicia (artículo 76 C.Pol.) ${ }^{32}$. Sin embargo,

\footnotetext{
${ }^{30}$ Soто KLoss, E., Temas fundamentales, cit. (n. 27), pp. 390-391.

${ }^{31}$ Ibíd., pp. 414-417.

${ }^{32}$ Véase, entre otras, la sentencia de la Corte Suprema en causa rol N ${ }^{\circ} 1074-2008$, de 12 de mayo de 2008, "Codelco División El Teniente con Dirección del Trabajo y otros". Sobre esta materia se puede consultar el trabajo de GAMONAL ConTreras,
} 
el alcance de estas sentencias debe ser relativizado, pues la ratio contenida en ellas no fue proyectada a otras materias donde se ejercen poderes similares de fiscalización y sanción por diversos órganos de la Administración del Estado $^{33}$. Por lo demás, también contiene un interesante voto de minoría ${ }^{34}$, además de existir otros pronunciamientos en sentido contrario. ${ }^{35}$

Esto exige determinar con precisión cómo se debe comprender la autotutela administrativa, con el objeto de determinar su fundamento constitucional.

\section{Auto-tutela administrativa y facultades jurisdiccionales.}

El problema central que plantea el principio de auto-tutela administrativa es su compatibilidad frente a un sistema constitucional que se construye sobre el principio de la hetero-tutela o hetero-composición, entregando al Estado, a través de los tribunales de justicia, el ejercicio del poder jurisdiccional: conocer las causas civiles y criminales, resolverlas y hacer ejecutar lo juzgado (artículo 76 C.Pol.). Por lo tanto, sostener que los órganos de la Administración del Estado pueden por sí y ante sí hacer “justicia”, es decir, conocer, resolver y ejecutar sus propias causas o en las que son partes, aparece

Sergio, Fiscalización, aplicación del Derecho laboral y acción de protección, en El Mismo, Trabajo y Derecho (Santiago, Abeledo Perrot, 2010), pp. 75-89.

${ }^{33}$ Así ocurre con el Servicio de Impuestos Internos (artículos 115 y 120 del Código del Trabajo); la Superintendencia de Valores y Seguros (artículo 30 del Decreto-ley N ${ }^{\circ}$ 3.538); la Superintendencia de Pensiones (artículo 18 del Decreto con fuerza de ley $\mathrm{N}^{\circ}$ 101, de 1980, del Ministerio del Trabajo y Previsión Social); la Superintendencia de Bancos e Instituciones Financieras (artículo 21 del Decreto-ley N ${ }^{\circ} 1.097$ ); la Superintendencia de Salud (artículo 112 del Decreto con fuerza de ley $\mathrm{N}^{\circ} 1$, de 2005, del Ministerio de Salud); el Servicio Nacional de Aduanas (artículo 184 del Decreto con fuerza de ley No 30, de 2004, del Ministerio de Hacienda), etc.

${ }^{34}$ Este corresponde al ministro Pedro Pierry Arrau, que ha sostenido que: "[...] la autoridad administrativa está facultada para calificar jurídicamente los hechos, siendo esto parte de la actividad administrativa. En efecto, es precisamente dicha calificación jurídica la que es indispensable para el ejercicio de esta actividad, en particular para la sanción administrativa, por lo que al hacerlo la Inspección del Trabajo no ha vulnerado lo dispuesto en el artículo $19 \mathrm{~N}^{\circ} 3$ inciso $4^{\circ}$ de la Constitución Politica de la República actuando como comisión especial, sino que lo ha hecho en el desempeño de una actividad administrativa".

${ }^{35}$ Véase la sentencia de la Corte Suprema rol No 3595-2008, de 6 de agosto de 2008, en la cual se sostuvo que la actuación del funcionario de la Dirección del Trabajo no ha invadido la competencia del Poder Judicial arrogándose facultades jurisdiccionales, pues se ha limitado a ejercer sus atribuciones y potestades de naturaleza administrativa, sancionando una infracción manifiesta a la legislación laboral; determinación que, por lo demás, es susceptible de impugnación ante los Juzgados del Trabajo, por lo que no se ha constituido en una comisión especial en detrimento de la garantía del Juez natural, prevista en el artículo $19 \mathrm{~N}^{\circ} 3$ inciso $4^{\circ} \mathrm{C}$.Pol. 
del todo equivoco, más aún cuando se afirma el pleno control judicial de las actuaciones de estas entidades (artículo $19 \mathrm{~N}^{\circ} 3$ y 38 C.Pol.).

Más equivoco aún también aparece el criterio sustentado en algunas sentencias de la Corte Suprema, que identifica las facultad de interpretar el Derecho con el ejercicio de potestades jurisdiccionales, llegando a afirmar que interpretar es juzgar. Por lo tanto, cuando los órganos de la Administración interpretan el Derecho, resuelven y ejecutan lo resuelto, estarían invadiendo las competencias propias de los órganos jurisdiccionales. ${ }^{36}$

A este respecto, se ha de reconocer que la denominación utilizada (autotutela administrativa) que pretende dar cuenta de la posición que tienen los órganos administrativos frente a los tribunales de justifica, tiene la virtud de explicar de forma gráfica las formas de actuación de estas entidades en ejercicio del poder público. No obstante, lleva al equívoco de entender que estos órganos ejercen justicia por su propia mano, es decir, una actividad de naturaleza jurisdiccional que está entregada a los tribunales de justicia. Este es quizás el principal reparo a la denominación utilizada para describir este fenómeno y, a la vez, el principal argumento para cuestionar su constitucionalidad.

En este punto, cabe preguntarse si efectivamente esto es así y, en caso contrario, plantear derechamente de qué estamos hablando. En primer término, no es posible sostener que las actuaciones formales de la Administración sean el ejercicio de facultades jurisdiccionales. En efecto, cuando un órgano administrativo conoce de un asunto de su competencia, interpreta las normas y adopta una determinación, sigue las etapas propias que demanda el razonamiento jurídico y la labor que corresponde a todo operador del Derecho. En este proceso necesariamente la determinación del sentido objetivo de las normas constituye un proceso intelectual necesario e ineludible, que no es sino la interpretación de dichas normas. Esto se traduce, a su vez, en las actuaciones formales propias de la Administración, como es el procedimiento y el acto administrativo. En este punto, la voluntad de la Administración se expresa en estos actos, que bajo ningún respecto pueden identificarse con actuaciones de naturaleza jurisdiccional, no sólo desde el punto de vista formal, sino también material. En efecto, los actos administrativos no tienen la fuerza obligatoria ni el efecto propio de una resolución judicial, como es resolver la cuestión con fuerza de cosa juzgada. Además, se trata de actos plenamente revisables por los tribunales de justica, quienes tendrán la última palabra para decidir sobre la validez o no de dichas actuaciones, sin ulterior recurso. Además, en este plano, la auto-tutela

${ }^{36}$ Véase la nota 34. Esto también se corresponde con la tesis sustentada por SoTo KLoss, E., Temas fundamentales, cit. (n. 27), pp. 390 ss. 
administrativa no puede ser considerada una actividad jurisdiccional pues, como bien señala Feliciano Benvenuti, la tutela jurisdiccional es siempre, por definición, imparcial, neutra o de tercero, mientras que la actuación de la Administración es siempre parcial. ${ }^{37}$

En definitiva, cuando los órganos administrativos ejercen sus potestades públicas, gozan de determinados privilegios que le permiten crear, modificar y extinguir situaciones jurídicas sin intervención de otros órganos y, a su vez, ejecutar materialmente sus propias decisiones, mediante actos que se presumen legales, sin que bajo ningún respecto constituyan actuaciones jurisdiccionales. A su vez, son los tribunales los que tendrán la última palabra para declarar, con fuerza de cosa juzgada, si dichas actuaciones son o no válidas.

\section{Auto-tutela y potestad sancionadora: losprincipios de eficacia y eficiencia} en el marco del bien común.

En el entendido que la auto-tutela administrativa no constituye stricto sensu una facultad de naturaleza jurisdiccional, cabe preguntarse las razones por las cuales el legislador puede entregar poderes sancionadores a la Administración, frente al ejercicio de poderes punitivos por parte de los tribunales de justicia. Ya hemos señalado que el Tribunal Constitucional ha sostenido que se trata de una facultad discrecional del legislador determinar si la represión y castigo de una determinada conducta puede canalizarse por la vía penal o por la vía administrativa, sujeto empero a algunos límites no menores.

Tal como lo plantea la doctrina moderna, el problema debe ser analizado desde la perspectiva del Derecho del Estado, considerando las funciones y deberes que el ordenamiento jurídico le ha impuesto, así como los instrumentos necesarios para cumplir dicha función. La posición que tiene el Estado frente al ser humano (servicialidad), el deber de promoción del bien común y de integración armónica de todos los sectores de la Nación que le impone la Carta fundamental (artículo 1), exigen que éste deba adoptar todas las medidas y ejercer las atribuciones que el ordenamiento jurídico le confiere destinadas a cumplir un rol de conformación social que responda a estos valores y bienes constitucionales. Estas exigencias han llegado a un crecimiento exponencial frente a una sociedad que se ha hecho más compleja desde la revolución industrial llegando a lo que se ha denominado la moderna sociedad del riesgo. Todo lo anterior ha demandado una intervención decidida del Estado mediante una acción oportuna y eficaz, la que muchas veces no se encuentra en la naturaleza, dinámica y ritualidad propia de los procesos

\footnotetext{
${ }^{37}$ Benvenuti, F., cit. (n. 29).
} 
judiciales y que exige, por lo tanto, asumir tal función a través de sus órganos administrativos, dejando para una segunda fase el control jurisdiccional. Esto coloca a la actividad judicial en una función subsidiaria, especialmente en lo que se refiere al Derecho penal, respondiendo a la idea de que la represión criminal tiene el carácter de ultima ratio frente a las otras medidas que puede adoptar el Estado para satisfacer y proteger determinados valores y bienes constitucionales. ${ }^{38}$

Estas ideas son recogidas en nuestro ordenamiento como principios básicos que rigen a la Administración Pública, dentro de una de las normas más importantes a las que se encuentra sometida: la Ley No 18.575: Orgánica constitucional de base generales de la administración del Estado, particularmente en sus artículos 3 inciso $2^{\circ}$ y 5 . En ellos se destacan los principios de servicialidad, eficacia y eficiencia de la acción administrativa, lo cual se traduce, en este caso, en el diseño de una política represiva que garantice un equilibrio entre una acción oportuna y eficaz de los órganos públicos y los derechos de las personas imputadas, más aún tratándose de sanciones que impliquen una privación de libertad y que requieren -por mandato constitucional y según la jurisprudencia de del Tribunal Constitucional- de un proceso ante una autoridad judicial independiente e imparcial.

\section{El ANÁlisis DESDE LA PERSPECTIVA DE LOS DERECHOS FUNDAMENTALES}

Conforme a lo que hemos analizado, la discusión relativa a la diferencia entre sanciones penales y sanciones administrativas es de larga data. Ahora bien, un criterio que debe descartarse de plano, por tener carácter meramente superficial, alude a la autoridad y técnicas de aplicación de las respectivas sanciones. A primera vista la diferencia más ostensible -y que parece darle el nombre a una de las dos categorías- radica en que, mientras que las sanciones penales son aplicadas por los tribunales, y por lo tanto requiere, previamente, un procedimiento jurisdiccional - las sanciones administrativas pueden ser aplicadas por órganos administrativos, no siendo requisito el antecedente del juicio previo para la juridicidad de su aplicación. Si bien esto corresponde a la práctica usual en el modelo de la organización de las administraciones públicas del Derecho continental, nada obsta a perseverar en la distinción -por las razones que se explicarán- entre sanciones administrativas y sanciones penales en un modelo en que todas las sanciones sean aplicadas en sede juris-

${ }^{38}$ Sobre esta materia véase: CORDERo, Eduardo, El Derecho administrativo sancionador y su relación con el Derecho penal, en Revista de Derecho de la Universidad Austral de Chile, 26 (2012) 2. 
diccional, desde un inicio. En el mismo ámbito de reflexión, no existe ningún argumento serio, de índole constitucional, que impida la configuración de un sancionatorio administrativo, con carácter ejecutorio, radicado en sede administrativa, mientras el afectado por una sanción administrativa conserve el acceso a la revisión judicial de la medida, y exista un procedimiento eficiente para hacer efectiva la responsabilidad de la Administración por los daños que hubiere podido provocar en la ejecución de las sanciones administrativas, si en definitiva se concluye su improcedencia y concurren elementos que permitan apreciar algún elemento de anti-juridicidad en el actuar administrativo (por ejemplo, infracciones al principio de proporcionalidad).

Otro criterio, frecuentemente invocado para distinguir entre sanciones penales y sanciones administrativas es aquél que apunta a la entidad del castigo. Seria propio y exclusivo de las sanciones penales la pena privativa de libertad (o de vida, en su caso), quedando en el ámbito de las sanciones administrativas la afectación de otros derechos, en especial aquellos de naturaleza patrimonial (para los individuos en general) y las posiciones jurídicas de naturaleza estatutaria (en el caso de funcionarios de las administraciones públicas). Si bien este criterio parece acercarse más a una distinción clara y difícilmente rebatible (no parece aceptable que por vía de la sanción administrativa los órgano de esa naturaleza apliquen una privación de libertad), lo cierto es que ello sólo ocurre porque da cuenta del fundamento más profundo de la distinción, que se encuentra en el ámbito de los derechos fundamentales.

Se ha señalado ya que la alusión a un eventual ius puniendi del Estado no representa una categoría idónea para apreciar la forma como el Estado ejerce sus potestades. Lo que se puede apreciar es que el Estado impone ciertas consecuencias para determinadas hipótesis; algunas de ellas como consecuencias a un actuar individual contrario a Derecho (sanciones en general), otras, simplemente, como forma de lograr los fines del Estado (cobro de impuestos, reclutamiento forzoso, restricciones al ejercicio de ciertos derechos). El intento de delimitación, sin embargo, es difícil de realizar si se trata de atender exclusivamente al carácter antijurídico de la conducta. Así, por ejemplo, la facultad de accionar ante tribunales para obtener la indemnización derivada de la responsabilidad contractual bien puede estimarse consecuencia de un actuar antijurídico (el respectivo incumplimiento contractual) o, simplemente, para hacer efectiva una de varias alternativas que tiene el deudor, con lo que el incumplimiento pierde el reproche desde la perspectiva jurídica la que, en la indemnización, se resuelve como éticamente neutra. Por lo tanto, resulta más adecuado examinar el ámbito de la conducta en que incide la consecuencia jurídica. Aquí radica la diferencia esencial entre las sanciones penales y otro tipo de sanciones (incluyendo las administrativas), así como 
el núcleo de la extensión del Derecho penal (frente a otras alternativas) en un Estado de Derecho.

Lo característico de la sanción penal es que ella opera como forma de prevenir, o castigar (dependiendo del enfoque) ciertas conductas específicas, en el ámbito de lo que se conoce como derecho de libertad general de los individuos. La libertad general corresponde al ámbito no juridificado de la conducta humana, y justifica lo que se conoce como el principio de distribución: mientras que los órganos públicos sólo pueden realizar aquello que el Derecho les permite, porque su existencia se debe al Derecho, los individuos pueden realizar todo aquello que el Derecho no les ha prohibido, porque su existencia no está jurídicamente condicionada. El individuo no se "despierta" conforme a Derecho, ni se lava (o no) los dientes conforme a la ley, ni decide (o no) tomar cereales o huevos revueltos al desayuno, y así sucesivamente. En éste ámbito -y mientras mantiene el carácter de conducta no juridificada - es donde entra a actuar el Derecho penal, para evitar/ castigar aquellas conductas, no reguladas, dentro de un universo idealmente infinito de posibilidad de conducta. Desde un punto de vista estrictamente jurídico, somos libres para cometer un delito. El delito no es una infracción a una norma jurídica de "buen comportamiento" preexistente; a lo más, el reproche puede hacerse desde la perspectiva moral. Radica aquí la opción por la libertad del Estado de Derecho, en contraposición al Estado Policíaco, que se atribuye facultades limitativas de la libertad individual a fin de evitar la producción de ciertos ilícitos. $Y$ es a consecuencia de esto que la sanción penal es privativa de libertad, a fin de ser congruente con dicho predicamento: se reconocen al individuo amplias posibilidades de conducta. Se definen algunas, muy precisamente (y de aquí la exigencia de tipicidad de la ley penal); el reproche para la incursión en ellas es, a su vez, la pérdida de libertad como posibilidad no limitada de conducta.

En contraposición a la estructura, así concebida, de la sanción penal, la sanción administrativa opera en otra dimensión. Se trata de ámbitos en que el Estado ha decidido entrar al ámbito de libertad general -y tratando de usar alguna una figura poética- ha tendido sobre ella la red del Derecho. A partir de ese momento, se imponen a los individuos, y aunque sólo sea en términos generales, ciertos deberes de actuación, de modo tal que su conducta puede ser calificada de jurídica o antijurídica de acuerdo a las reglas con las que el Estado ha buscado dirigir la conducta. La sanción administrativa corresponde a la consecuencia jurídica por un actuar que puede calificarse, en estricto rigor, como antijurídico, porque infringe un deber susceptible de ser entendido como parte del ordenamiento jurídico vigente. En un nivel de mayor especificidad, la sanción administrativa en sentido estricto, esto es, la aplicable a quienes se encuentran en una relación estatutaria con las 
administraciones públicas, expresa esta misma estructura en el contexto de los deberes estatutarios.

La importancia de este enfoque puede apreciarse fácilmente en sus consecuencias. Explica por qué se producen las características arriba descritas y que tradicionalmente se han tomado por criterios de distinción entre sanciones penales y administrativas. Pero, con mayor sentido práctico, permite reflexionar sobre dos puntos que son trascendentes en el uso de la herramienta que es la sanción administrativa para el funcionamiento del Estado Moderno. En primer lugar, las exigencias de tipicidad propias de la sanción penal se explican porque la conducta sancionada es una entre muchas posibilidades cercanas .no castigadas- en el universo de la libertad general. De este modo, resulta imperativo aislar, por medio de una precisa descripción, la o las conductas que se trata de sancionar penalmente. En cambio, en el ámbito de la sanción administrativa, si bien una adecuada tipificación puede ser un elemento del derecho al debido proceso sustantivo, es perfectamente posible concebir técnicas de sanción que reposen, a lo menos parcialmente, en la existencia de deberes de conducta que los individuos debían seguir ( $\sin$ que sea necesario especificar cada una de las posibilidades concretas de infracción a dichos deberes). En segundo lugar, la sanción penal, al aislar una conducta que no se encuentra contextualizada por deberes de conducta preexistentes, sólo puede incorporar de manera específica y limitada los elementos que deben incidir en la calificación de dicha conducta (atenuantes y agravantes). En contrario, y por contraste, el ámbito de la sanción penal permite un margen de aplicación del principio de proporcionalidad en concreto a la relación existente entre la infracción cometida y la sanción aplicada, ya sea respecto de su oportunidad, ya sea respecto de su intensidad, en aquellos casos en que admite gradación.

\section{Conclusiones}

La discusión en torno a las bases constitucionales de las sanciones administrativas se ha desarrollado en Chile a partir de un cuestionamiento a los privilegios y prerrogativas que se reconoce a la Administración, a pesar que la jurisprudencia administrativa, judicial y constitucional no ha planteado en general mayores reparos.

Sin embargo, el análisis se ha hecho necesario para entroncar las potestades sancionadoras administrativas en el marco de los principios básicos que rigen a los órganos administrativos, particularmente la denominada potestad de auto-tutela administrativa, para determinar su naturaleza y alcance, con el objeto de deslindarla claramente del ejercicio de facultades jurisdiccionales y comprender cuál es su fundamento en el marco de una mayor interven- 
ción del Estado frente a un sociedad cada vez más compleja y generadora de mayores riesgos.

En la medida que no se plantea como un problema de naturaleza constitucional la existencia de estos poderes punitivos, la cuestión se traslada a lo que la Carta Fundamental ha resuelto sobre la materia, especialmente en relación a los límites que se impone al legislador. En este punto, el Tribunal Constitucional reconoce que corresponde al legislador determinar la política represiva y establecer que conductas serán sancionadas por la vía penal o por la vía administrativa. A su vez, se establecen una serie de límites centrados en la proporcionalidad y las medidas privativas de libertad como una cuestión de competencia exclusiva de los jueces.

De este forma, el legislador puede establecer esta política represiva en base a los principios de eficacia y eficiencia en el actuar el Estado respecto de determinadas conductas que requieren de una acción oportuna (sanciones administrativas), frente a medidas que -dada su gravedad- exigen de una mayor rigurosidad en sus procedimientos y la intervención de un órgano independiente e imparcial, como es la autoridad judicial (sanción penal). Esto último refuerza la idea de un Derecho penal subsidiario y establece pautas de actuación objetiva a las que debe someterse el legislador.

Por último, tanto las sanciones administrativas y las penas deben ser entendidas como medios y no como fines, destinada a que el Estado resguarde determinados valores y principios, ya sea bajo la forma de derechos, bienes jurídicos o de una actuación que permita efectivamente crear las condiciones para que todas las personas se desarrollen plenamente, tanto espiritual y materialmente, bajo el concepto de bien común. Esto permite proyectar un interesante análisis sustancialista que guía al legislador a partir de los derechos fundamentales, especialmente con la libertad como elemento rector de los delitos y la imposición de deberes previamente establecidos, en el caso de las sanciones administrativas.

\section{BiBLIOgRAFÍA}

Aguerrea Mella, Pedro, El estatuto constitucional de la penas. Su aplicación a las sanciones administrativas conforme a los antecedentes de la Comisión de Estudio de la Nueva Constitución, en AA.VV. Sanciones Administrativas y Derechos fundamentales: regulación y nuevo intervencionismo (Santiago, Universidad Santo Tomás, 2005).

Aróstica Maldonado, Iván, Problemas del Derecho Administrativo Penal, Revista de Derecho, Universidad de Concepción, 182 (1987).

Aróstica Maldonado, Iván, Un Lustro de Sanciones Administrativas (1988-1992), Revista de Derecho Público, 50 (1991), p. 173 y ss.

Aylwin, Patricio, Derecho Administrativo (2 Tomos, Santiago, Editorial Universitaria, 1959). 
Benvenuti, Feliciano, Voz “Autotutela (dirittoamministrativo)”, en Enciclopedia del Diritto (Milán, Giuffré, 1959).

Cordero, Eduardo, El Derecho administrativo sancionador y su relación con el Derecho penal, en Revista de Derecho, Universidad Austral de Chile, 26, № 2 (2012).

Ferrada Bórquez, Juan Carlos, Las potestades y privilegios de la Administración Pública en el Régimen Administrativo Chileno, en Revista de Derecho, Universidad Austral de Chile, XX, 2, (diciembre 2007).

Ferrada Bórquez, Juan Carlos, Losprincipios estructurales del Derecho Administrativo chileno: un análisis comparativo, Revista de Derecho, Universidad de Concepción, 221-222, LXXV, (enero-diciembre 2007).

Gamonal Contreras, Sergio, Fiscalización, aplicación del Derecho laboraly acción de protección, en Del Mismo Autor, Trabajo y Derecho (Santiago, Abeledo Perrot, 2010).

García de Enterría, Eduardo y Fernández, Tomás-Ramón, Curso de Derecho Administrativo (10a edición, T. I, Madrid, Civitas, 2001).

GARCÍA DE ENTERRÍA, Eduardo, La formación histórica del principio de autotutela de la Administración, en Moneda y Crédito, 128 (1974).

GARCÍA DE ENTERRÍA, Eduardo, El problema jurídico de las sanciones administrativas, en Revista de Derecho Administrativo, 10 (1976)

GARCÍA DE ENTERRÍA, Eduardo,Revolución francesa y Administración contemporánea ( $2^{\mathrm{a}}$ ed., Madrid, Taurus, 1981).

Huergo Lora, Alejandro, Las sanciones administrativas (Madrid, Iustel, 2007).

Huneeus, Jorge, La Constitución ante el Congreso (2 vol., Santiago, Imprenta de Los Tiempos, 1879).

Mattes, Hans, Problemas de Derecho Penal Administrativo, Madrid, Revista de Derecho Privado, 1979.

Nieto, Alejandro, Derecho Administrativo Sancionador (4a edición, Madrid, Tecnos, 2011).

Prado, Santiago, Principios elementales de Derecho Administrativo chileno (Santiago, Imprenta Nacional, 1859).

RADBRUCH, Gustav, Introducción a la Filosofía del Derecho (México, Fondo de Cultura Económica, 2005).

Rodríguez Collado, Luis, Bases para distinguir entre infracciones criminales y administrativas, Revista de Derecho, Pontificia Universidad Católica de Valparaíso, XI (1987).

Román Cordero, Cristian, Derecho Administrativo Sancionador: ¿Ser o no ser? He aqui el dilema, en Pantoja, rol ando (coord.), Derecho Administrativo. 120 años de Cátedra (Santiago, Editorial Jurídica de Chile), pp. 107-141.

Silva Cimma, Enrique, Derecho Administrativo chileno y comparado. Introducción y Fuentes ( 5 a edición, Santiago, Editorial Jurídica de Chile, 2009).

Soто Kloss, Eduardo, Derecho Administrativo (Santiago, Editorial Jurídica de Chile, 1992).

Soто Kloss, Eduardo, Derecho Administrativo, Temas Fundamentales (Santiago, Legalpublishing, 2009), pp. 389-398.

Soto Kloss, Eduardo, El derecho administrativo penal (Notas para el estudio de la potestad sancionadora de la Administración), Boletín de Investigaciones, Facultad de Derecho, Universidad Católica de Chile, 44-45, (1979/80), pp. 95-103

Sото KLoss, Eduardo, La potestad sancionadora de la Administración, ¿Se adecua a la 
Constitución? (Conferencias Santo Tomás, Sanciones Administrativas y Derechos fundamentales: regulación y nuevo intervencionismo, Santiago, Academia de Derecho, Universidad Santo Tomás, 2005), pp. 29-49.

VAras, Guillermo, Derecho Administrativo (Santiago, Editorial Nascimento, 1940) 
